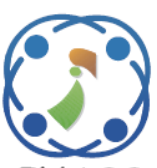

\title{
The Fuzzy Multi-attribute Group Decision Making to Determine a Syndrome Differentiation in Traditional Chinese Medicine Perspective
}

\author{
I Gusti Putu Asto Buditjahjanto ${ }^{1 *}$ \\ ${ }^{1}$ Universitas Negeri Surabaya, Indonesia \\ * Corresponding author's Email: asto@unesa.ac.id
}

\begin{abstract}
The Fuzzy Multi-attribute Group Decision Making (FMAGDM) has been used to assist people in making decisions for sophisticated problems. In Traditional Chinese Medicine (TCM), decision making is used to select the syndrome differentiation of a patient. If the TCM physicians or practitioners are mistaken to determine the syndrome differentiation of a patient can cause wrong in the medication. Conventionally, the problem in TCM is the difficulty in determining a syndrome differentiation of patients. The difficulty is because the numbers of symptoms are numerous and these symptoms are correlated directly to syndrome differentiation. Even some symptoms in one syndrome can emerge from other syndromes. Therefore, the TCM physicians or practitioners must capable to identify the type of symptoms that correlated to the syndrome. The objective of this research is to use FMAGDM to determine the syndrome differentiation in the lung organ from the TCM perspective. Lung syndrome differentiation has five syndromes and 18 symptoms. This research is composed of three methods such as a Fuzzy Linguistic, FMAGDM, and Simple Additive Weighting. The fuzzy set is utilized to capture the experts' linguistic preference toward the severity level of symptoms, FMAGDM is utilized to build the weight matrix of the experts and Simple Additive Weighting is utilized to select the syndrome differentiation of the patient through selecting the highest preference value of the expert of lung syndrome differentiation. By using data from 9 lung syndrome patients who had different symptoms, the FMAGDM simulation results showed that FMAGDM can determine the type of lung syndrome suffered by each patient. The FMAGDM simulation results for the 9 patients were the same as the diagnosis result of a physician exactly. This shows that FMAGDM can determine the type of lung syndrome as well.
\end{abstract}

Keywords: Fuzzy, Multi-attribute decision making, Simple additive weighting, Traditional Chinese medicine, Group decision making.

\section{Introduction}

A Multi-Attribute Decision Making (MADM) has been used by people in helping to make decisions in many fields. There are some applications of MADM in selecting a decision, MADM was used to improve the resource utilization efficiency of the logistics industry [1], to determine the communication network [2], to solve a problem in selecting the supplier of the new energy vehicles for sustainability [3], and to apply to the supplier selection problem of automotive parts suppliers [4]. MADM has advantages in simplicity and accuracy in making decisions [5]. MADM able to offer decisionmakers to give their preferences toward the availability of several alternative solutions and also able to helps them in determine the best decision from the alternative solutions.

When decision making involves several decisionmakers, it can consider the selection of better alternatives for decision making on complex problems. This process is known as Group DecisionMaking (GDM). According to reference [6] explained GDM as a process in which some individuals interact with each other to evaluate problems to be able to supply available alternative solutions and to select the best among alternative solutions that are corresponding with the problems. Meanwhile, according to [7] the process of GDM was to integrate individual preference that varies from one 
to another, among some alternative solutions to be one group preference to solve a problem solution.

Decision-makers with their preference able to provide a broader view or understanding of the problem at hand and able to offer some alternative solutions associated with the criteria of the problem. The preference of decision-makers is usually still in the form of linguistic preferences so that it is still in the form of inexact and vague [8]. Fuzzy logic can translate the linguistic preferences into quantitative form. Therefore, fuzzy logic can solve the linguistic preference problem in decision making. Fuzzy MAGDM, one of the fuzzy decision-making types, can overcome the problem of linguistic preferences in decision making which consists of some decisionmakers. Fuzzy MAGDM translates the linguistic preferences of decision-makers into fuzzy logic.

Researches that used multi-attribute decision making for the analysis and diagnosis of diseases and syndromes in TCM is still not much. This is because there are many obstacles to implement or resolve TCM problems. Reference [9] stated that TCM has some problems because its variety is very large and complex. Furthermore, TCM physicians' problems are they have difficulty to diagnose diseases and prescribe TCM drugs effectively and efficiently because of the large volume of TCM data. In TCM, decision-making is also needed by TCM physicians and TCM practitioners to diagnosis a syndrome. Diagnosis is done through two steps, the first step is to collect patients' information related to their complaint and the second step is to determine and select the right syndrome differentiation of patients based on the symptoms. In the second step, decision making is carried out to determine a syndrome differentiation suffered by the patient. Syndrome differentiation is to classify a disease by grouping patients into dissimilar categories based on symptoms [10].

Therefore, syndrome differentiation to determine the disease requires a lot of experience, and time consumes to decide a disease syndrome for beginner TCM physicians or practitioners. TCM is an empirical study with long-term clinical practice to develop associated theories [11]. This is because the TCM physicians or practitioners must capable to identify syndrome differentiation through the symptoms that arise from the patient [12]. The problem in TCM is how to determine the syndrome type of disease exactly. The syndrome always has some accompanying symptoms. Meanwhile, those symptoms that appear can be numerous and even existing in other syndromes. The complexity and the number of symptoms can make confuse the TCM physicians or practitioners in determining the type of syndrome of a disease.

The severity levels of a disease symptom of patients can be measured through observation, anamnesis, and palpation. Therefore, the subjectivity and vague elements are still high in the detection of these symptoms by TCM physicians or practitioners. Therefore, it needs a method that can help TCM physicians or practitioners in determining the severity levels of a disease symptom. The use of fuzzy sets can help in identifying the severity levels of a disease symptom. Fuzzy sets can translate qualitative linguistic preferences into quantitative in the form of fuzzy numbers.

This research aims to develop a decision support system for TCM physicians or TCM practitioners in determining the syndrome differentiation in the lung organs by using the fuzzy MAGDM method. The method is a combination of fuzzy linguistic preferences and a rating system to rate some decisions from a group of TCM experts. This fuzzy preference is used to capture experts' preferences in decision making to provide consistency of solutions for sophisticated problems, especially in TCM diagnosis. The fuzzy MAGDM method is used to solve this problem. The fuzzy MAGDM method has a decision matrix that consists of some attributes (symptoms) and weight preferences of the experts. Then, this decision matrix is converted into importance weight combined with a rating preference to determine the ranking of the type of lung syndrome. The highest weight becomes the decision in determining the type of lung syndrome.

This research is organized as follows. Section 2 explains the related material and method. Section 3 explains the proposed methodology. Section 4 presents the conducted simulation and obtained results. Finally, Section 5 presents the conclusion of this research and future work suggestions.

\section{Literature review}

\subsection{Syndromes and symptoms}

The basic concept of TCM is to apply the Yin Yang balance theory, the five elements that represent elements on earth, namely fire, metal, water, wood, and earth. These five elements represent organs in the human body. According to [13] symptoms are external manifestations of an illness such as headache, chills, chills, heat. Besides, the syndromes are the condition caused by the disease, its nature, the infected area, and the relationship between diseasecausing factors and the energy contained in the patient. Therefore, it can be interpreted that the 
syndrome has a range or a broader and comprehensive view of disease.

The determination of the syndrome differentiation helps facilitate the determination of therapy. Generally, most diseases cover all pathological processes, while the syndrome differentiation only describes the stages of the disease. The determination or classification of syndromes differentiation in TCM consists of [14] The classification of syndromes is based on Cang $\mathrm{Fu}$ organ abnormalities such as Cang organs include lungs, heart, spleen, kidney, and liver, Fu organs include Large intestine, small intestine, stomach, bladder, and bile; b) The classification of syndromes is based on meridian abnormalities such as reaction to stress, abnormalities in the smooth flow of Qi in the meridians, abnormalities in the direction of Qi flow in the meridians; c) Classification of the syndrome according to 6 meridians d) The classification of syndromes according to Ying, Wei, Qi, and Sie.

\subsection{Fuzzy set}

A fuzzy set consists of several member elements that the membership degree varying in its set. The membership degree value of an element has an interval between 0 until 1 . The popular fuzzy number is a triangular fuzzy number due to the simplicity in modeling and ease of interpretation [15]. The membership function and the characteristics of the triangular fuzzy number $\mu_{\widetilde{A}}(x)=\left(A_{1}, S_{1}, T_{1}\right)$ are formulated by Eq. (1) and Fig. 1.

$$
\mu_{\tilde{A}}=\left\{\begin{array}{l}
\frac{x-A}{S-A}, A \ll x \ll S \\
\frac{T-x}{T-S}, S \ll x \ll T \\
0, \quad \text { otherwise }
\end{array}\right.
$$

Let $\mu_{\widetilde{B}}(x)=\left(A_{2}, S_{2}, T_{2}\right)$ then, the basic operators of algebraic triangular fuzzy numbers (TFN) are:

Fuzzy numbers addition: $\mu_{\widetilde{A}}(x)+\mu_{\widetilde{B}}(x)$

$$
\left(A_{1}, S_{1}, T_{1}\right)+\left(A_{2}, S_{2}, T_{2}\right)=\left(A_{1}+A_{2}, S_{1}+S_{2}, T_{1}+T_{2}\right)(2)
$$

Fuzzy numbers subtraction: $\mu_{\widetilde{A}}(x)-\mu_{\widetilde{B}}(x)$

$$
\left(A_{1}, S_{1}, T_{1}\right)-\left(A_{2}, S_{2}, T_{2}\right)=\left(A_{1}-A_{2}, S_{1}-S_{2}, T_{1}-T_{2}\right)
$$

Fuzzy numbers multiplication: $\mu_{\widetilde{A}}(x) \times \mu_{\widetilde{B}}(x)$

$$
\left(A_{1}, S_{1}, T_{1}\right) x\left(A_{2}, S_{2}, T_{2}\right)=\left(A_{1} x A_{2}, S_{1} x S_{2}, T_{1} x T_{2}\right)
$$

Fuzzy numbers division: $\mu_{\widetilde{A}}(x) / \mu_{\widetilde{B}}(x)$

$$
\left(A_{1}, S_{1}, T_{1}\right) /\left(A_{2}, S_{2}, T_{2}\right)=\left(A_{1} / A_{2}, S_{1} / S_{2}, T_{1} / T_{2}\right) .
$$

\subsection{Fuzzy preferences linguistic}

The fuzzy set can translate the preferences of experts in assessing a problem that is uncertain and vague. By using the fuzzy set, linguistic preferences from experts can be quantified in weight values between 0 to 1 [16]. Reference [17] stated that if $R$ is a variable come from a set $L=\left\{l_{1}, l_{2}, l_{3} \ldots l_{i}\right\}$, where $l_{i}$ is a label of linguistic explaining the relation of preference. The experts select a value from the set $L$ for describing their valuation of preference for each pair of alternatives. Reference [17] gives an example of the set L with 13 labels of linguistic. Next, the experts can reveal their fuzzy relations of preference as follows:

$$
R_{k}\left(s_{i}, s_{j}\right)=\left(r_{i j}^{k}\right)=
$$

\section{$D P$, if $s_{i}$ is prefered to $s_{j}$ in definite degree}

$V H P$, if $s_{i}$ is prefered to $s_{j}$ in very high degree $H P$, if $s_{i}$ is prefered to $s_{j}$ in high degree

$M P$, if $s_{i}$ is prefered to $s_{j}$ in moderate degree $L P$, if $s_{i}$ is prefered to $s_{j}$ in low degree $V L P$, if $s_{i}$ is prefered to $s_{j}$ in very low degree $\left\{A S\right.$, if $s_{i}$ is about the same as (indifferent to) $s_{j}$ $V L D$, if $s_{j}$ is prefered to $s_{i}$ in very low degree $L D$, if $s_{j}$ is prefered to $s_{i}$ in low degree $M D$, if $s_{j}$ is prefered to $s_{i}$ in moderate degree $H D$, if $s_{j}$ is prefered to $s_{i}$ in high degree $V H D$, if $s_{j}$ is prefered to $s_{i}$ in very high degree $D D$, if $s_{j}$ is prefered to $s_{i}$ in definite degree

Where $R_{k}$ is a preference relations matrix for individual $k$ whose variable $r_{i j}^{k}$ is from $r_{i j}^{k}=$ $\mu_{R k}\left(s_{i}, s_{j}\right)$. A set of $n$ alternatives, $S=\left\{s_{1}, s_{2}, \ldots, s_{3}\right\}$, and a set of $m$ expert, $I=\{1,2, \ldots, m\}$. Each expert $k \in I$ defines the expert's preference toward $S$.

\subsection{Multi-attribute decision making and group decision making}

The following matrix is to represent the MADM problems [18]:

$$
\begin{aligned}
D & =\begin{array}{c}
A_{1} \\
A_{2} \\
\vdots \\
A_{m}
\end{array}\left(\begin{array}{cccc}
x_{11} & x_{12} & \ldots & x_{1 n} \\
x_{12} & x_{22} & \cdots & x_{2 n} \\
\vdots & \vdots & \vdots & \vdots \\
x_{1 n} & x_{2 n} & \cdots & x_{m n}
\end{array}\right) \\
W & =\left(w_{1}, w_{2}, \cdots, w_{n}\right)
\end{aligned}
$$


where $A_{1}, A_{2}, \ldots, A_{m}$ are a viable alternative, for $C_{l}$, $C_{2}, \ldots, C_{n}$ is the attribute (criterion), and $x_{i j}$ is the performance rating of the i-alternative that relates with the jth attribute. Whereas $w_{j}$ is the jth attribute weight. There are two main categories to classify the attributes such as the benefit attribute and the cost attribute, in the evaluation of MADM. The benefit attributes are used when a higher score is set to an alternative for rank higher performance, which is the maximum $j$-th attribute. Whereas the cost attributes are used for a higher score and are set to an alternative for rank lower performance, which is the minimum $j$ th attribute.

Decision making with only a single decisionmaker to provide solutions to complex problems still causes some inconsistencies and biases. Decision making with a group of decision-makers or known as Group Decision Making (GDM) can provide consistency of solutions for the sophisticated problems that are emerged. The decision-makers give their judgment to the problem, so the consistency of the solution can be taken from the decision making. Reference [19] stated that GDM is the method of attaining a solution for a complicated problem of making decisions that utilized the consideration and response of several decision-makers.

Multi-attribute group decision making (MAGDM) is a group of people to make the best decision for a MADM subject. To achieve the best solution from some optional solutions, MAGDM decision-makers have to approve with certain rules to follow. The decision-making process on problems in people and organizations is not only in the form of a decision between yes and no but has involved the level of decision-makers' preferences to assess for subjective attributes. Fuzzy sets can translate the level of preference of each decision-maker to assess for subjective attributes. The combination of using fuzzy in MADM problems using group decisions is called fuzzy MAGDM [20]. The objective of Fuzzy MAGDM is to confront the ranking problem from vague information and fuzzy preferences of multiple experts, which are declared for subjective attributes [21].

\subsection{Simple additive weighting}

The Simple Additive Weighting (SAW) method is a simple attribute-taking technique based on a weighted average. The SAW method is often used in MADM problems. Each alternative is multiplied with the scale value given to the alternative to get an evaluation score. The SAW application requires some steps as follows: to determinate objectives and alternatives, to evaluate alternatives, to determinate sub-objective weights, to aggregate weighted partial preference values, and to calculate sensitive analysis. Direct assessment is carried out at standardized scales on qualitative attributes. Attributes assessment is gained by normalized the attribute values to fit on a standardized scale. In the decision matrix, all elements are on a comparable scale. A comparable scale $\left(r_{i j}\right)$ is obtained for benefit criteria that can be seen in Eq. (8) and cost criteria can be seen in Eq. (9) [22].

$$
\begin{aligned}
& r_{i j}=\frac{x_{i j}}{x_{j}^{\max }} \\
& r_{i j}=\frac{x_{j}^{\text {min }}}{x_{j}}
\end{aligned}
$$

$r_{i j}$ is a normalized performance appraisal of several $\mathrm{A}_{\mathrm{i}}$ alternatives on the $C_{i}$ attribute, to be known that $i=1,2, \ldots, m$ and $j=1,2, \ldots, n$. User preference values for each $V_{i}$ alternative are given as:

$$
V_{i}=\sum_{j=1}^{n} w_{j} r_{i j}
$$

The largest value of $V_{i}$ indicates that an alternative $A_{i}$ will be chosen.

\section{Proposed methodology}

The description of Fuzzy MAGDM elements is as follows, the syndrome (S) is defined as an alternative to be selected as differentiation syndrome of a patient. Next, the symptoms or criteria (C) are defined as an attribute or criteria that emerge on the diagnosis. This research is limited only to studying the type of lung syndrome. The identification of lung syndrome and its symptoms are based on the research of [23].

The lung syndrome consists of five syndromes such as 1) invasion of the lungs by the cold wind (S1), 2 ) accumulation of heat in the lungs (S2), 3) retention of moist phlegm in the lungs (S3), 4) lung qi

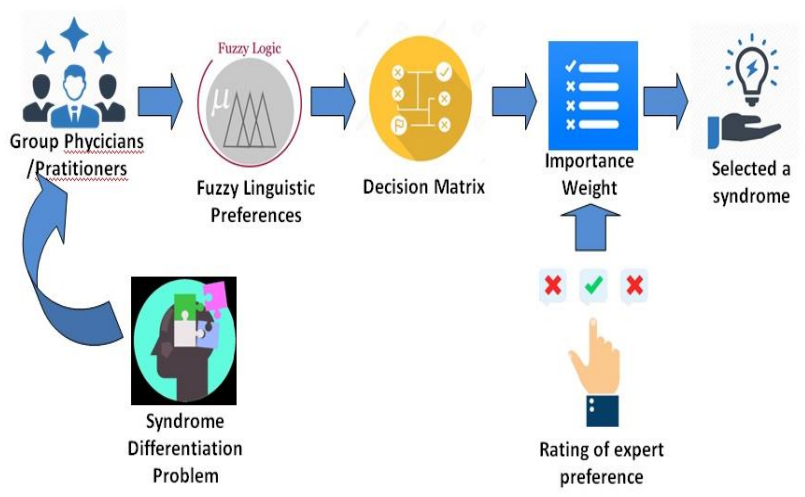

Figure. 1 Research steps to gain syndrome differentiation 
Table 1. The importance weight of linguistic variables and fuzzy numbers

\begin{tabular}{|c|c|}
\hline Linguistic Variables & Fuzzy Numbers \\
\hline Very Severe $\left(\mathrm{VS}_{\mathrm{v}}\right)$ & $(0.75,1.00,1.00)$ \\
\hline Severe $\left(\mathrm{S}_{\mathrm{v}}\right)$ & $(0.50,0.75,1.00)$ \\
\hline Quite Severe $\left(\mathrm{QS}_{\mathrm{v}}\right)$ & $(0.25,0.50,0.75)$ \\
\hline Not Severe $(\mathrm{NS})$ & $(0.00,0.25,0.50)$ \\
\hline Not Exist $(\mathrm{NE})$ & $(0.00,0.00,0.25)$ \\
\hline
\end{tabular}

deficiency (S4) and 5) lung yin deficiency (S5). Meanwhile, the symptoms are chills (C1), fever (C2); headache (C3), nasal discharge (C4), cough (C5), yellow sputum(C6), dry nose (C7), epistaxis (C8), sore throat (C9), constipation (C10), shortness of breath $(\mathrm{C} 11)$, weak voice $(\mathrm{C} 12)$, pale complexion (C13), lassitude (C14), dry throat (C15), hoarse voice (C16), orthopnoea (C17), fullness in the chest (C18).

This study consisted of 3 steps, namely 1) the rating step, 2) the aggregation step, and 3) the selection step. Fig. 1 indicates the research steps. The stage of rating state consists of gathering opinions from three experts through a questionnaire. The rating is rated by three experts consisting of 2 acupuncture physicians and an acupuncture practitioner who works at the LP3A (Acupuncture Services Research Development Laboratory) in Surabaya-Indonesia. The filling out of the questioner is in linguistic preferences as shown in the first column in Table 1. Meanwhile, the second column is a fuzzy number, which is a conversion from linguistic preferences.

This research gives the experts the selection of simple linguistic variables. To state their preferences related to the importance of various influential factors such as criteria/attributes, and then these linguistic preferences variables are parameterized using TFN as seen in Fig. 2. This research used TFN because it has some advantages such as Triangular shapes represent fuzzy numbers and the simplest shapes and TFN can express the ambiguity and uncertainty of complex data more accurately [24], TFN does not only offer a range of fuzzy points but also comprises the three

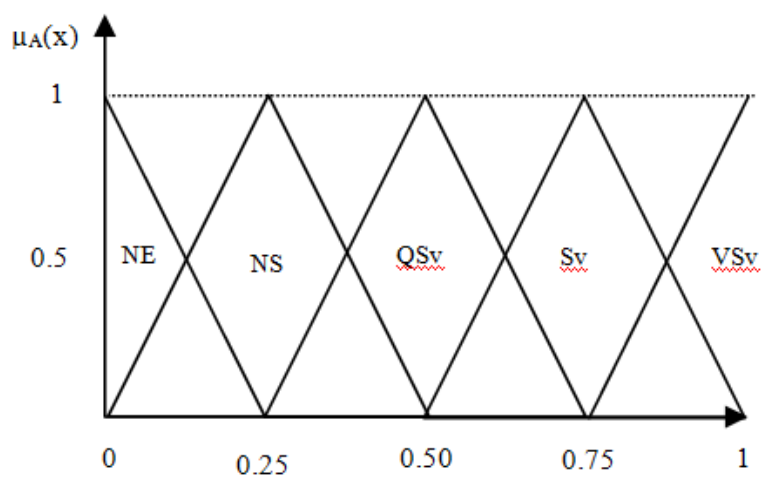

Figure. 2 TFN of linguistic preference most representative fuzzy points, which play an important role in explaining the information that still fuzzy [25].

When criteria/attributes are selected and the scale of corresponding linguistic is established, then the importance weights for every criterion/attributes can be achieved. The determining of the criteria or attributes of the importance weights, the procedure is explained:

1) Compose a decision matrix $\tilde{X}$ for criteria/attributes of the importance weights $\left(\mathrm{Cr}_{j}\right.$, $j=1,2, \ldots, n)$. Afterward, the expert $(E i, i=$ $1,2, \ldots, m)$ provide their judgment in linguistic terms for the importance weight of each criterion/attributes [26], which is

$$
\begin{aligned}
& \begin{array}{lllll}
E 1 & E 2 & E 3 & \ldots & E m
\end{array}
\end{aligned}
$$

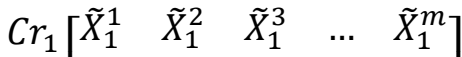

$$
\begin{aligned}
& \begin{array}{llllll}
C r_{2} & \tilde{X}_{2}^{1} & \tilde{X}_{2}^{1} & \tilde{X}_{3}^{1} & \ldots & \tilde{X}_{2}^{m}
\end{array}
\end{aligned}
$$

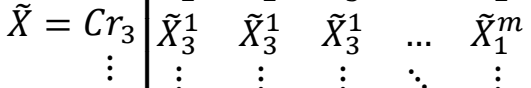

$$
\begin{aligned}
& C r_{n}\left[\begin{array}{ccccc}
\tilde{X}_{n}^{1} & \tilde{X}_{n}^{1} & \tilde{X}_{n}^{1} & \ldots & \tilde{X}_{n}^{m}
\end{array}\right]
\end{aligned}
$$

where $i=1,2, \ldots . m$ and $j=1,2, \ldots, n$.

To be known that $m$ indicates the expert number and $n$ is the criteria/attributes number, $\tilde{x}_{j}^{i}=$ $\left(A x_{j}^{i}, S x_{j}^{i}, \mathrm{~T} x_{j}^{i}\right)$ represent the fuzzy outcome value of jth criteria/attributes assessed by $i$-th expert

2) Because the judgment of each expert is varied following their expectation, knowledge, experience, understanding, A method of the average score is used to integrate the experts' fuzzy performance values, which is

$$
\widetilde{\omega}_{j}=\frac{1}{m}\left[\sum_{i=1}^{m} \tilde{x}_{j}^{i}\right]
$$

where $\widetilde{\omega}_{j=\left(L \omega_{j}, M \omega_{j}, U \omega_{j}\right)}$ represents the fuzzy performance weight of jth criteria/attributes.

3) After defuzzification, converse the triangular fuzzy numbers that have been aggregated into the value of Best Nonfuzzy Performance (BNP) [27], $\mathrm{BNP}_{\mathrm{W}_{\mathrm{j}}}$ is taken to represent the grade of BNP for the TFN $\widetilde{\omega}_{J}$, which is

$$
B N P w_{J}=\frac{\left[\left(U \omega_{J}-L \omega_{J}\right)+\left(M \omega_{J}-L \omega_{J}\right)\right]}{3}+L \omega_{J}
$$

where $\mathrm{BNPw}_{j}$ is the crisp number of importance weight of $j$ th criteria/attributes.

4) After these TFN are defuzzified, crisp numbers of importance weight are put together and then normalized those numbers. Then, $r_{j}$ is set to 
denote the normalized importance weight of $j$ th criteria/attributes, as shown in Eq. (8) and Eq. (9). Then to select the lung syndrome differentiation, Eq. (10) is used to rank the higher value for each type of lung syndrome differentiation.

\section{Result and discussion}

This research was conducted using Fuzzy MAGDM methods to build an importance weight $\left(r_{j}\right)$, following by a rating of expert (TCM physician/practitioner) preference $\left(w_{j}\right)$. Then, a SAW method was used to determine the selection of lung syndrome differentiation. The details of the results of the research are as follows:

Step 1- Rating Step

This stage assesses the expert's judgment of their preference toward each symptom (criteria/attribute) of the lung syndrome differentiation (alternative). The assessment is conducted by using the linguistic preference as indicated in Table 1. The experts consist of three experts, two TCM physicians, and one TCM practitioner. Table 2 indicates a decision matrix as a rating result of the experts' linguistics preferences.

The next procedure is to convert the experts' linguistic preferences to be Triangular Fuzzy Number (TFN). For example, if the expert linguistic preference is $\mathrm{S}$ (Severe) then the TFN is $(0.50,0.75$, 1.00 ), and so on. Table 2 is the conversion of the rating results of the experts from linguistic preferences into the form of TFN.

Step 2-Aggregating Step

In this stage, the procedure is to construct a fuzzy rating matrix through Best Non-fuzzy Performance. Table 3 indicates the calculation result of aggregated decision and $W_{j}$ is an aggregated decision matrix.

Next, for criteria or attributes (symptom) normalization $\left(r_{i j}\right)$, it is only used the benefit criteria used Eq. (8). Because the higher the weight level of a symptom that arises from a syndrome, then this symptom will be dominant compared to other symptoms so that it will contribute to the calculation determining which syndrome will have the highest weighting value. Table 4 indicates the calculation result of the benefit criteria/attributes known as normalized importance weight.

Step 3- Selection step

The rating of expert preference $\left(w_{j}\right)$ is the weight given by the TCM physician/practitioner in diagnosing a patient.

The following is a simulation of the TCM practitioner who gives his rating linguistic preferences toward a patient with identity $\mathrm{P} 17$ as seen in Table 5. Table 5 indicates the TCM practitioner's (the expert) linguistic preferences toward symptoms. The matrix of the TCM practitioner preferences rating is as follows:

$\tilde{X}=\left(\mathrm{NE}, \mathrm{NE}, \mathrm{NE}, \mathrm{NE}, \mathrm{S}_{\mathrm{v}}, \mathrm{S}_{\mathrm{v}}, \mathrm{NE}, \mathrm{NE}, \mathrm{NE}, \mathrm{NE}, \mathrm{NE}\right.$, $\left.\mathrm{NE}, \mathrm{VS}_{\mathrm{v}}, \mathrm{NE}, \mathrm{NE}, \mathrm{VS}_{\mathrm{v}}, \mathrm{NE}, \mathrm{NE}\right)$

Then convert the rating of the TCM practitioner linguistic preferences to the fuzzy performance values as follows:

$\widetilde{\omega}_{j}=((0.00,0.00,0.25),(0.00,0.00,0.25),(0.00,0.00$, $0.25),(0.00,0.00,0.25),(0.50,0.75,1.00),(0.50$, $0.75,1.00),(0.00,0.00,0.25),(0.00,0.00,0.25)$, $(0.00,0.00,0.25),(0.00,0.00,0.25),(0.00,0.00$, $0.25),(0.00,0.00,0.25),(0.75,1.00,1.00),(0.00$, $0.00,0.25),(0.00,0.00,0.25),(0.75,1.00,1.00)$, $(0.00,0.00,0.25),(0.00,0.00,0.25))$

Next, convert the fuzzy performance values to be a rating of the TCM practitioner preference as follows:

$w_{j}=(0.08,0.08,0.08,0.08,0.75,0.75,0.08,0.08$, $0.08,0.08,0.08,0.08,0.92,0.08,0.08,0.92,0.08$, $0.08)$

Once the normalized importance weights $\left(r_{j}\right)$ and the rating of the TCM practitioner preference are calculated $\left(w_{j}\right)$ then multiply the importance weights of criteria/attributes by the rating of the TCM practitioner preference then the lung syndrome differentiation can be obtained. In this step, the SAW method is used to determine lung syndrome differentiation. The selection is based on the highest-ranking of the TCM practitioner preference values for each $V_{i}$ alternatives. The alternative preference values of $V_{i}$ are as follows:

$$
V=\left(\begin{array}{lllll}
2.23 & 2.59 & 2.49 & 2.58 & \mathbf{3 . 0 2}
\end{array}\right)
$$

As we can see that the highest-ranking of the alternatives is the fifth alternative (V5) which means that the lung syndrome differentiation is 'lung yin deficiency (S5)'. To simulation this research, the researcher used data from the LP3A (Laboratory of Research and Development Acupuncture Service) Surabaya - Indonesia [28]. The total datasheets of patients were more than 100 , while the patients showing symptoms of the lung syndrome were 9 patients. Furthermore, these datasheets of 9 patients were used to demonstrate the Fuzzy MAGDM simulation in determining the type of lung syndrome 
Table 2. The decision matrix the experts' linguistics preferences and TFN

\begin{tabular}{|c|c|c|c|c|c|c|c|c|c|}
\hline E1 & $\mathrm{Cr}_{1}$ & $\mathrm{Cr}_{2}$ & $\mathrm{Cr}_{3}$ & $\mathrm{Cr}_{4}$ & $\mathrm{Cr}_{5}$ & Cr6 & $\mathrm{Cr}_{7}$ & Cr8 & Cr9 \\
\hline S1 & $\begin{array}{c}\mathrm{S}_{\mathrm{v}}(0.50 \\
0.75 \\
1.00)\end{array}$ & $\begin{array}{c}\mathrm{S}_{\mathrm{v}}(0.50, \\
0.75 \\
1.00)\end{array}$ & $\begin{array}{c}\mathrm{S}_{\mathrm{v}}(0.50 \\
0.75 \\
1.00)\end{array}$ & $\begin{array}{c}\mathrm{VS}_{\mathrm{v}} \\
(0.75, \\
1.00 \\
1.00)\end{array}$ & $\begin{array}{l}\mathrm{VS}_{\mathrm{v}} \\
(0.75, \\
1.00, \\
1.00)\end{array}$ & $\begin{array}{c}\mathrm{VS}_{\mathrm{v}} \\
(0.75, \\
1.00, \\
1.00)\end{array}$ & $\begin{array}{c}\text { NS }(0.00 \\
0.25 \\
0.50)\end{array}$ & $\begin{array}{c}\text { NS }(0.00 \\
0.25 \\
0.50)\end{array}$ & $\begin{array}{c}\text { NS }(0.00 \\
0.25 \\
0.50)\end{array}$ \\
\hline S2 & $\begin{array}{c}\mathrm{QS}_{\mathrm{v}} \\
(0.25, \\
0.50 \\
0.75)\end{array}$ & $\begin{array}{c}\mathrm{VS}_{\mathrm{v}} \\
(0.75, \\
1.00 \\
1.00)\end{array}$ & $\begin{array}{c}\text { NS }(0.00, \\
0.25 \\
0.50)\end{array}$ & $\begin{array}{c}\mathrm{VS}_{\mathrm{v}} \\
(0.75, \\
1.00, \\
1.00)\end{array}$ & $\begin{array}{c}\mathrm{S}_{\mathrm{v}}(0.50 \\
0.75 \\
1.00)\end{array}$ & $\begin{array}{c}\mathrm{S}_{\mathrm{v}}(0.50 \\
0.75 \\
1.00)\end{array}$ & $\begin{array}{c}\mathrm{VS}_{\mathrm{v}} \\
(0.75, \\
1.00, \\
1.00)\end{array}$ & $\begin{array}{c}\mathrm{QS}_{\mathrm{v}} \\
(0.25, \\
0.50, \\
0.75)\end{array}$ & $\begin{array}{c}\mathrm{VS}_{\mathrm{v}} \\
(0.75, \\
1.00 \\
1.00)\end{array}$ \\
\hline S3 & $\begin{array}{c}\text { NS }(0.00 \\
0.25 \\
0.50)\end{array}$ & $\begin{array}{c}\text { NS }(0.00 \\
0.25 \\
0.50)\end{array}$ & $\begin{array}{c}\text { NS }(0.00 \\
0.25 \\
0.50)\end{array}$ & $\begin{array}{c}\text { NS }(0.00 \\
0.25 \\
0.50)\end{array}$ & $\begin{array}{l}\mathrm{VS}_{\mathrm{v}} \\
(0.75, \\
1.00, \\
1.00)\end{array}$ & $\begin{array}{l}\mathrm{VS}_{\mathrm{v}} \\
(0.75 \\
1.00 \\
1.00)\end{array}$ & $\begin{array}{c}\text { NS }(0.00 \\
0.25 \\
0.50)\end{array}$ & $\begin{array}{c}\text { NS }(0.00 \\
0.25 \\
0.50)\end{array}$ & $\begin{array}{c}\text { NS }(0.00 \\
0.25 \\
0.50)\end{array}$ \\
\hline S4 & $\begin{array}{c}\text { NS }(0.00 \\
0.25 \\
0.50)\end{array}$ & $\begin{array}{c}\text { NS }(0.00 \\
0.25 \\
0.50)\end{array}$ & $\begin{array}{c}\text { NS }(0.00 \\
0.25 \\
0.50)\end{array}$ & $\begin{array}{c}\text { NS }(0.00 \\
0.25 \\
0.50)\end{array}$ & $\begin{array}{l}\mathrm{VS}_{\mathrm{v}} \\
(0.75, \\
1.00, \\
1.00)\end{array}$ & $\begin{array}{c}\text { NS }(0.00 \\
0.25 \\
0.50)\end{array}$ & $\begin{array}{c}\text { NS }(0.00 \\
0.25 \\
0.50)\end{array}$ & $\begin{array}{c}\text { NS }(0.00 \\
0.25 \\
0.50)\end{array}$ & $\begin{array}{c}\text { NS }(0.00 \\
0.25 \\
0.50)\end{array}$ \\
\hline S5 & $\begin{array}{c}\text { NS }(0.00 \\
0.25 \\
0.50)\end{array}$ & $\begin{array}{c}\mathrm{VS}_{\mathrm{v}} \\
(0.75, \\
1.00, \\
1.00)\end{array}$ & $\begin{array}{c}\text { NS }(0.00 \\
0.25 \\
0.50)\end{array}$ & $\begin{array}{c}\text { NS }(0.00 \\
0.25 \\
0.50)\end{array}$ & $\begin{array}{c}\mathrm{VS}_{\mathrm{v}} \\
(0.75, \\
1.00 \\
1.00)\end{array}$ & $\begin{array}{c}\text { NS }(0.00 \\
0.25 \\
0.50)\end{array}$ & $\begin{array}{c}\text { NS }(0.00 \\
0.25 \\
0.50)\end{array}$ & $\begin{array}{c}\text { NS }(0.00 \\
0.25 \\
0.50)\end{array}$ & $\begin{array}{c}\mathrm{QS}_{\mathrm{v}} \\
(0.25, \\
0.50 \\
0.75)\end{array}$ \\
\hline E1 & Cr10 & $\mathrm{Cr}_{11}$ & $\mathrm{Cr}_{12}$ & $\mathrm{Cr}_{13}$ & $\mathrm{Cr}_{14}$ & $\mathrm{Cr}_{15}$ & $\mathrm{Cr}_{16}$ & $\mathrm{Cr}_{17}$ & $\mathrm{Cr}_{18}$ \\
\hline S1 & $\begin{array}{c}\text { NS }(0.00 \\
0.25 \\
0.50)\end{array}$ & $\begin{array}{c}\text { NS }(0.00 \\
0.25 \\
0.50)\end{array}$ & $\begin{array}{c}\text { NS }(0.00 \\
0.25 \\
0.50)\end{array}$ & $\begin{array}{c}\text { NS }(0.00 \\
0.25 \\
0.50)\end{array}$ & $\begin{array}{c}\text { NS }(0.00 \\
0.25 \\
0.50)\end{array}$ & $\begin{array}{c}\text { NS }(0.00 \\
0.25 \\
0.50)\end{array}$ & $\begin{array}{c}\text { NS }(0.00 \\
0.25 \\
0.50)\end{array}$ & $\begin{array}{c}\text { NS }(0.00 \\
0.25 \\
0.50)\end{array}$ & $\begin{array}{c}\text { NS }(0.00 \\
0.25 \\
0.50)\end{array}$ \\
\hline S2 & $\begin{array}{c}\mathrm{S}_{\mathrm{v}}(0.50 \\
0.75 \\
1.00)\end{array}$ & $\begin{array}{c}\text { NS }(0.00 \\
0.25 \\
0.50)\end{array}$ & $\begin{array}{c}\text { NS }(0.00, \\
0.25 \\
0.50)\end{array}$ & $\begin{array}{c}\text { NS }(0.00 \\
0.25 \\
0.50)\end{array}$ & $\begin{array}{c}\text { NS }(0.00 \\
0.25 \\
0.50)\end{array}$ & $\begin{array}{c}\text { NS }(0.00 \\
0.25 \\
0.50)\end{array}$ & $\begin{array}{c}\text { NS }(0.00 \\
0.25 \\
0.50)\end{array}$ & $\begin{array}{c}\text { NS }(0.00 \\
0.25 \\
0.50)\end{array}$ & $\begin{array}{c}\text { NS }(0.00 \\
0.25 \\
0.50)\end{array}$ \\
\hline S3 & $\begin{array}{c}\text { NS }(0.00 \\
0.25 \\
0.50)\end{array}$ & $\begin{array}{c}\mathrm{VS}_{\mathrm{v}} \\
(0.75 \\
1.00 \\
1.00)\end{array}$ & $\begin{array}{c}\text { NS }(0.00 \\
0.25 \\
0.50)\end{array}$ & $\begin{array}{c}\text { NS }(0.00 \\
0.25 \\
0.50)\end{array}$ & $\begin{array}{c}\text { NS }(0.00 \\
0.25 \\
0.50)\end{array}$ & $\begin{array}{c}\text { NS }(0.00 \\
0.25 \\
0.50)\end{array}$ & $\begin{array}{c}\text { NS }(0.00 \\
0.25 \\
0.50)\end{array}$ & $\begin{array}{c}\mathrm{VS}_{\mathrm{v}} \\
(0.75 \\
1.00 \\
1.00)\end{array}$ & $\begin{array}{c}\mathrm{S}_{\mathrm{v}}(0.50 \\
0.75 \\
1.00)\end{array}$ \\
\hline S4 & $\begin{array}{c}\text { NS }(0.00 \\
0.25 \\
0.50)\end{array}$ & $\begin{array}{c}\mathrm{VS}_{\mathrm{v}} \\
(0.75, \\
1.00, \\
1.00)\end{array}$ & $\begin{array}{c}\mathrm{VS}_{\mathrm{v}} \\
(0.75, \\
1.00, \\
1.00)\end{array}$ & $\begin{array}{c}\mathrm{VS}_{\mathrm{v}} \\
(0.75, \\
1.00, \\
1.00)\end{array}$ & $\begin{array}{c}\mathrm{VS}_{\mathrm{v}} \\
(0.75, \\
1.00, \\
1.00)\end{array}$ & $\begin{array}{c}\text { NS }(0.00 \\
0.25 \\
0.50)\end{array}$ & $\begin{array}{c}\text { NS }(0.00 \\
0.25 \\
0.50)\end{array}$ & $\begin{array}{c}\text { NS }(0.00 \\
0.25 \\
0.50)\end{array}$ & $\begin{array}{c}\text { NS }(0.00 \\
0.25 \\
0.50)\end{array}$ \\
\hline S5 & $\begin{array}{c}\text { NS }(0.00 \\
0.25 \\
0.50)\end{array}$ & $\begin{array}{c}\text { NS }(0.00 \\
0.25 \\
0.50)\end{array}$ & $\begin{array}{c}\text { NS }(0.00 \\
0.25 \\
0.50)\end{array}$ & $\begin{array}{c}\text { NS }(0.00 \\
0.25 \\
0.50)\end{array}$ & $\begin{array}{c}\text { NS }(0.00 \\
0.25 \\
0.50)\end{array}$ & $\begin{array}{c}\mathrm{VS}_{\mathrm{v}} \\
(0.75, \\
1.00, \\
1.00)\end{array}$ & $\begin{array}{c}\mathrm{S}_{\mathrm{v}}(0.50 \\
0.75 \\
1.00)\end{array}$ & $\begin{array}{c}\text { NS }(0.00 \\
0.25 \\
0.50)\end{array}$ & $\begin{array}{c}\text { NS }(0.00 \\
0.25 \\
0.50)\end{array}$ \\
\hline E2 & $\mathrm{Cr}_{1}$ & $\mathrm{Cr}_{2}$ & $\mathrm{Cr}_{3}$ & $\mathrm{Cr}_{4}$ & $\mathrm{Cr}_{5}$ & Cr6 & $\mathrm{Cr}_{7}$ & Cr8 & Cr9 \\
\hline S1 & $\begin{array}{c}\mathrm{QS}_{\mathrm{v}} \\
(0.25, \\
0.50, \\
0.75)\end{array}$ & $\begin{array}{c}\mathrm{S}_{\mathrm{v}}(0.50, \\
0.75 \\
1.00)\end{array}$ & $\begin{array}{c}\text { NS }(0.00 \\
0.25 \\
0.50)\end{array}$ & $\begin{array}{c}\mathrm{VS}_{\mathrm{v}} \\
(0.75, \\
1.00, \\
1.00)\end{array}$ & $\begin{array}{c}\mathrm{VS}_{\mathrm{v}} \\
(0.75, \\
1.00, \\
1.00)\end{array}$ & $\begin{array}{c}\mathrm{QS}_{\mathrm{v}} \\
(0.25, \\
0.50, \\
0.75)\end{array}$ & $\begin{array}{c}\text { NS }(0.00 \\
0.25 \\
0.50)\end{array}$ & $\begin{array}{c}\text { NS }(0.00 \\
0.25 \\
0.50)\end{array}$ & $\begin{array}{c}\text { NS }(0.00 \\
0.25 \\
0.50)\end{array}$ \\
\hline S2 & $\begin{array}{c}\mathrm{S}_{\mathrm{v}}(0.50 \\
0.75 \\
1.00)\end{array}$ & $\begin{array}{c}\mathrm{QS}_{\mathrm{v}} \\
(0.25, \\
0.50, \\
0.75)\end{array}$ & $\begin{array}{c}\text { NS }(0.00, \\
0.25 \\
0.50)\end{array}$ & $\begin{array}{c}\mathrm{VS}_{\mathrm{v}} \\
(0.75, \\
1.00, \\
1.00)\end{array}$ & $\begin{array}{l}\mathrm{VS}_{\mathrm{v}} \\
(0.75, \\
1.00 \\
1.00)\end{array}$ & $\begin{array}{c}\mathrm{VS}_{\mathrm{v}} \\
(0.75, \\
1.00, \\
1.00)\end{array}$ & $\begin{array}{c}\mathrm{VS}_{\mathrm{v}} \\
(0.75, \\
1.00, \\
1.00)\end{array}$ & $\begin{array}{c}\mathrm{QS}_{\mathrm{v}} \\
(0.25, \\
0.50, \\
0.75)\end{array}$ & $\begin{array}{l}\mathrm{VS}_{\mathrm{v}} \\
(0.75, \\
1.00 \\
1.00)\end{array}$ \\
\hline S3 & $\begin{array}{c}\text { NS }(0.00 \\
0.25 \\
0.50)\end{array}$ & $\begin{array}{c}\text { NS }(0.00 \\
0.25 \\
0.50)\end{array}$ & $\begin{array}{c}\text { NS }(0.00, \\
0.25 \\
0.50)\end{array}$ & $\begin{array}{c}\text { NS }(0.00 \\
0.25 \\
0.50)\end{array}$ & $\begin{array}{c}\mathrm{VS}_{\mathrm{v}} \\
(0.75, \\
1.00, \\
1.00)\end{array}$ & $\begin{array}{c}\mathrm{S}_{\mathrm{v}}(0.50 \\
0.75 \\
1.00)\end{array}$ & $\begin{array}{c}\text { NS }(0.00 \\
0.25 \\
0.50)\end{array}$ & $\begin{array}{c}\text { NS }(0.00 \\
0.25 \\
0.50)\end{array}$ & $\begin{array}{c}\text { NS }(0.00, \\
0.25 \\
0.50)\end{array}$ \\
\hline S4 & $\begin{array}{c}\text { NS }(0.00 \\
0.25 \\
0.50)\end{array}$ & $\begin{array}{c}\text { NS }(0.00, \\
0.25 \\
0.50)\end{array}$ & $\begin{array}{c}\text { NS }(0.00, \\
0.25 \\
0.50)\end{array}$ & $\begin{array}{c}\text { NS }(0.00 \\
0.25 \\
0.50)\end{array}$ & $\begin{array}{c}\mathrm{VS}_{\mathrm{v}} \\
(0.75, \\
1.00, \\
1.00)\end{array}$ & $\begin{array}{c}\text { NS }(0.00 \\
0.25 \\
0.50)\end{array}$ & $\begin{array}{c}\text { NS }(0.00 \\
0.25 \\
0.50)\end{array}$ & $\begin{array}{c}\text { NS }(0.00 \\
0.25 \\
0.50)\end{array}$ & $\begin{array}{c}\text { NS }(0.00 \\
0.25 \\
0.50)\end{array}$ \\
\hline
\end{tabular}




\begin{tabular}{|c|c|c|c|c|c|c|c|c|c|}
\hline S5 & $\begin{array}{c}\text { NS }(0.00 \\
0.25 \\
0.50)\end{array}$ & $\begin{array}{c}\mathrm{VS}_{\mathrm{v}} \\
(0.75, \\
1.00, \\
1.00)\end{array}$ & $\begin{array}{c}\text { NS }(0.00 \\
0.25 \\
0.50)\end{array}$ & $\begin{array}{c}\text { NS }(0.00 \\
0.25 \\
0.50)\end{array}$ & $\begin{array}{c}\mathrm{VS}_{\mathrm{v}} \\
(0.75, \\
1.00 \\
1.00)\end{array}$ & $\begin{array}{c}\mathrm{VS}_{\mathrm{v}} \\
(0.75, \\
1.00, \\
1.00)\end{array}$ & $\begin{array}{c}\text { NS }(0.00 \\
0.25 \\
0.50)\end{array}$ & $\begin{array}{c}\text { NS }(0.00 \\
0.25 \\
0.50)\end{array}$ & $\begin{array}{c}\mathrm{S}_{\mathrm{v}}(0.50 \\
0.75 \\
1.00)\end{array}$ \\
\hline E2 & $\mathrm{Cr}_{10}$ & $\mathbf{C r}_{11}$ & $\mathbf{C r}_{12}$ & $\mathrm{Cr}_{13}$ & $\mathrm{Cr}_{14}$ & $\mathrm{Cr}_{15}$ & $\mathrm{Cr}_{16}$ & $\mathrm{Cr}_{17}$ & $\mathrm{Cr}_{18}$ \\
\hline S1 & $\begin{array}{c}\text { NS }(0.00 \\
0.25 \\
0.50)\end{array}$ & $\begin{array}{c}\text { NS }(0.00 \\
0.25 \\
0.50)\end{array}$ & $\begin{array}{c}\text { NS }(0.00, \\
0.25 \\
0.50)\end{array}$ & $\begin{array}{c}\text { NS }(0.00 \\
0.25 \\
0.50)\end{array}$ & $\begin{array}{c}\text { NS }(0.00 \\
0.25 \\
0.50)\end{array}$ & $\begin{array}{c}\text { NS }(0.00 \\
0.25 \\
0.50)\end{array}$ & $\begin{array}{c}\text { NS }(0.00 \\
0.25 \\
0.50)\end{array}$ & $\begin{array}{c}\text { NS }(0.00 \\
0.25 \\
0.50)\end{array}$ & $\begin{array}{c}\mathrm{NS}(0.00 \\
0.25 \\
0.50) \\
\end{array}$ \\
\hline $\mathbf{S 2}$ & $\begin{array}{c}\mathrm{S}_{\mathrm{v}}(0.50 \\
0.75 \\
1.00)\end{array}$ & $\begin{array}{c}\text { NS }(0.00 \\
0.25 \\
0.50)\end{array}$ & $\begin{array}{c}\text { NS }(0.00 \\
0.25 \\
0.50)\end{array}$ & $\begin{array}{c}\text { NS }(0.00 \\
0.25 \\
0.50)\end{array}$ & $\begin{array}{c}\text { NS }(0.00 \\
0.25 \\
0.50)\end{array}$ & $\begin{array}{c}\text { NS }(0.00 \\
0.25 \\
0.50)\end{array}$ & $\begin{array}{c}\text { NS }(0.00 \\
0.25 \\
0.50)\end{array}$ & $\begin{array}{c}\text { NS }(0.00 \\
0.25 \\
0.50)\end{array}$ & $\begin{array}{c}\text { NS }(0.00 \\
0.25 \\
0.50)\end{array}$ \\
\hline S3 & $\begin{array}{c}\text { NS }(0.00 \\
0.25 \\
0.50)\end{array}$ & $\begin{array}{c}\mathrm{VS}_{\mathrm{v}} \\
(0.75, \\
1.00, \\
1.00)\end{array}$ & $\begin{array}{c}\text { NS }(0.00, \\
0.25 \\
0.50)\end{array}$ & $\begin{array}{c}\text { NS }(0.00 \\
0.25 \\
0.50)\end{array}$ & $\begin{array}{c}\text { NS }(0.00 \\
0.25 \\
0.50)\end{array}$ & $\begin{array}{c}\text { NS }(0.00, \\
0.25 \\
0.50)\end{array}$ & $\begin{array}{c}\text { NS }(0.00 \\
0.25 \\
0.50)\end{array}$ & $\begin{array}{c}\mathrm{VS}_{\mathrm{v}} \\
(0.75, \\
1.00, \\
1.00)\end{array}$ & $\begin{array}{c}\mathrm{VS}_{\mathrm{v}} \\
(0.75, \\
1.00, \\
1.00)\end{array}$ \\
\hline S4 & $\begin{array}{c}\text { NS }(0.00 \\
0.25 \\
0.50)\end{array}$ & $\begin{array}{c}\mathrm{VS}_{\mathrm{v}} \\
(0.75, \\
1.00, \\
1.00)\end{array}$ & $\begin{array}{l}\mathrm{VS}_{\mathrm{v}} \\
(0.75, \\
1.00, \\
1.00)\end{array}$ & $\begin{array}{l}\mathrm{VS}_{\mathrm{v}} \\
(0.75, \\
1.00 \\
1.00)\end{array}$ & $\begin{array}{c}\mathrm{VS}_{\mathrm{v}} \\
(0.75, \\
1.00 \\
1.00)\end{array}$ & $\begin{array}{c}\text { NS }(0.00 \\
0.25 \\
0.50)\end{array}$ & $\begin{array}{c}\text { NS }(0.00 \\
0.25 \\
0.50)\end{array}$ & $\begin{array}{c}\text { NS }(0.00 \\
0.25 \\
0.50)\end{array}$ & $\begin{array}{c}\mathrm{VS}_{\mathrm{v}} \\
(0.75, \\
1.00, \\
1.00)\end{array}$ \\
\hline S5 & $\begin{array}{c}\text { NS }(0.00 \\
0.25 \\
0.50)\end{array}$ & $\begin{array}{c}\text { NS }(0.00 \\
0.25 \\
0.50)\end{array}$ & $\begin{array}{c}\text { NS }(0.00, \\
0.25 \\
0.50)\end{array}$ & $\begin{array}{c}\text { NS }(0.00 \\
0.25 \\
0.50)\end{array}$ & $\begin{array}{c}\text { NS }(0.00 \\
0.25 \\
0.50)\end{array}$ & $\begin{array}{c}\mathrm{VS}_{\mathrm{v}} \\
(0.75, \\
1.00, \\
1.00)\end{array}$ & $\begin{array}{c}\mathrm{VS}_{\mathrm{v}} \\
(0.75, \\
1.00, \\
1.00)\end{array}$ & $\begin{array}{c}\text { NS }(0.00, \\
0.25 \\
0.50)\end{array}$ & $\begin{array}{c}\text { NS }(0.00 \\
0.25 \\
0.50)\end{array}$ \\
\hline E3 & $\mathrm{Cr}_{1}$ & $\mathrm{Cr}_{2}$ & $\mathrm{Cr}_{3}$ & $\mathrm{Cr}_{4}$ & $\mathrm{Cr}_{5}$ & $\mathrm{Cr}_{6}$ & $\mathrm{Cr}_{7}$ & $\mathrm{Cr}_{8}$ & $\mathrm{Cr}_{9}$ \\
\hline S1 & $\begin{array}{c}\mathrm{QS}_{\mathrm{v}} \\
(0.25, \\
0.50, \\
0.75)\end{array}$ & $\begin{array}{c}\mathrm{S}_{\mathrm{v}}(0.50 \\
0.75 \\
1.00)\end{array}$ & $\begin{array}{c}\mathrm{QS}_{\mathrm{v}} \\
(0.25, \\
0.50 \\
0.75)\end{array}$ & $\begin{array}{c}\mathrm{QS}_{\mathrm{v}} \\
(0.25, \\
0.50, \\
0.75)\end{array}$ & $\begin{array}{c}\mathrm{QS}_{\mathrm{v}} \\
(0.25 \\
0.50 \\
0.75)\end{array}$ & $\begin{array}{c}\mathrm{QS}_{\mathrm{v}} \\
(0.25, \\
0.50, \\
0.75)\end{array}$ & $\begin{array}{c}\text { NS }(0.00 \\
0.25 \\
0.50)\end{array}$ & $\begin{array}{c}\text { NS }(0.00, \\
0.25 \\
0.50)\end{array}$ & $\begin{array}{c}\text { NS }(0.00 \\
0.25 \\
0.50)\end{array}$ \\
\hline S2 & $\begin{array}{c}\mathrm{S}_{\mathrm{v}}(0.50 \\
0.75 \\
1.00)\end{array}$ & $\begin{array}{c}\mathrm{QS}_{\mathrm{v}} \\
(0.25, \\
0.50 \\
0.75)\end{array}$ & $\begin{array}{c}\text { NS }(0.00, \\
0.25 \\
0.50)\end{array}$ & $\begin{array}{c}\mathrm{VS}_{\mathrm{v}} \\
(0.75, \\
1.00, \\
1.00)\end{array}$ & $\begin{array}{c}\mathrm{S}_{\mathrm{v}}(0.50, \\
0.75 \\
1.00)\end{array}$ & $\begin{array}{c}\mathrm{S}_{\mathrm{v}}(0.50 \\
0.75 \\
1.00)\end{array}$ & $\begin{array}{c}\mathrm{VS}_{\mathrm{v}} \\
(0.75, \\
1.00, \\
1.00)\end{array}$ & $\begin{array}{c}\mathrm{VS}_{\mathrm{v}} \\
(0.75, \\
1.00, \\
1.00)\end{array}$ & $\begin{array}{c}\mathrm{QS}_{\mathrm{v}} \\
(0.25, \\
0.50, \\
0.75)\end{array}$ \\
\hline S3 & $\begin{array}{c}\text { NS }(0.00 \\
0.25 \\
0.50)\end{array}$ & $\begin{array}{c}\text { NS }(0.00 \\
0.25 \\
0.50)\end{array}$ & $\begin{array}{c}\text { NS }(0.00 \\
0.25 \\
0.50)\end{array}$ & $\begin{array}{c}\text { NS }(0.00 \\
0.25 \\
0.50)\end{array}$ & $\begin{array}{c}\mathrm{S}_{\mathrm{v}}(0.50 \\
0.75 \\
1.00)\end{array}$ & $\begin{array}{c}\mathrm{VS}_{\mathrm{v}} \\
(0.75, \\
1.00, \\
1.00)\end{array}$ & $\begin{array}{c}\text { NS }(0.00 \\
0.25 \\
0.50)\end{array}$ & $\begin{array}{c}\text { NS }(0.00 \\
0.25 \\
0.50)\end{array}$ & $\begin{array}{c}\text { NS }(0.00 \\
0.25 \\
0.50)\end{array}$ \\
\hline S4 & $\begin{array}{c}\text { NS }(0.00 \\
0.25 \\
0.50)\end{array}$ & $\begin{array}{c}\text { NS }(0.00 \\
0.25 \\
0.50)\end{array}$ & $\begin{array}{c}\text { NS }(0.00, \\
0.25 \\
0.50)\end{array}$ & $\begin{array}{c}\text { NS }(0.00 \\
0.25 \\
0.50)\end{array}$ & $\begin{array}{c}\mathrm{QS}_{\mathrm{v}} \\
(0.25, \\
0.50, \\
0.75)\end{array}$ & $\begin{array}{c}\text { NS }(0.00, \\
0.25 \\
0.50)\end{array}$ & $\begin{array}{c}\text { NS }(0.00 \\
0.25 \\
0.50)\end{array}$ & $\begin{array}{c}\text { NS }(0.00, \\
0.25 \\
0.50)\end{array}$ & $\begin{array}{c}\text { NS }(0.00 \\
0.25 \\
0.50)\end{array}$ \\
\hline S5 & $\begin{array}{c}\text { NS }(0.00 \\
0.25 \\
0.50)\end{array}$ & $\begin{array}{c}\mathrm{VS}_{\mathrm{v}} \\
(0.75, \\
1.00, \\
1.00)\end{array}$ & $\begin{array}{c}\text { NS }(0.00, \\
0.25 \\
0.50)\end{array}$ & $\begin{array}{c}\text { NS }(0.00 \\
0.25 \\
0.50)\end{array}$ & $\begin{array}{c}\mathrm{VS}_{\mathrm{v}} \\
(0.75, \\
1.00, \\
1.00)\end{array}$ & $\begin{array}{c}\mathrm{VS}_{\mathrm{v}} \\
(0.75, \\
1.00, \\
1.00)\end{array}$ & $\begin{array}{c}\text { NS }(0.00 \\
0.25 \\
0.50)\end{array}$ & $\begin{array}{c}\text { NS }(0.00, \\
0.25 \\
0.50)\end{array}$ & $\begin{array}{c}\text { NS }(0.00 \\
0.25 \\
0.50)\end{array}$ \\
\hline E3 & $\mathrm{Cr}_{10}$ & $\mathrm{Cr}_{11}$ & $\mathrm{Cr}_{12}$ & $\mathrm{Cr}_{13}$ & $\mathrm{Cr}_{14}$ & $\mathrm{Cr}_{15}$ & $\mathrm{Cr}_{16}$ & $\mathrm{Cr}_{17}$ & $\mathrm{Cr}_{18}$ \\
\hline S1 & $\begin{array}{c}\text { NS }(0.00 \\
0.25 \\
0.50) \\
\end{array}$ & $\begin{array}{c}\text { NS }(0.00 \\
0.25 \\
0.50) \\
\end{array}$ & $\begin{array}{c}\text { NS }(0.00, \\
0.25 \\
0.50)\end{array}$ & $\begin{array}{c}\text { NS }(0.00 \\
0.25 \\
0.50) \\
\end{array}$ & $\begin{array}{c}\text { NS }(0.00 \\
0.25 \\
0.50) \\
\end{array}$ & $\begin{array}{c}\text { NS }(0.00, \\
0.25 \\
0.50) \\
\end{array}$ & $\begin{array}{c}\text { NS }(0.00 \\
0.25 \\
0.50) \\
\end{array}$ & $\begin{array}{c}\text { NS }(0.00 \\
0.25 \\
0.50) \\
\end{array}$ & $\begin{array}{c}\text { NS }(0.00 \\
0.25 \\
0.50)\end{array}$ \\
\hline S2 & $\begin{array}{c}\mathrm{QS}_{\mathrm{v}} \\
(0.25, \\
0.50, \\
0.75)\end{array}$ & $\begin{array}{c}\text { NS }(0.00 \\
0.25 \\
0.50)\end{array}$ & $\begin{array}{c}\text { NS }(0.00 \\
0.25 \\
0.50)\end{array}$ & $\begin{array}{c}\text { NS }(0.00 \\
0.25 \\
0.50)\end{array}$ & $\begin{array}{c}\text { NS }(0.00 \\
0.25 \\
0.50)\end{array}$ & $\begin{array}{c}\text { NS }(0.00 \\
0.25 \\
0.50)\end{array}$ & $\begin{array}{c}\text { NS }(0.00 \\
0.25 \\
0.50)\end{array}$ & $\begin{array}{c}\text { NS }(0.00 \\
0.25 \\
0.50)\end{array}$ & $\begin{array}{c}\text { NS }(0.00 \\
0.25 \\
0.50)\end{array}$ \\
\hline S3 & $\begin{array}{c}\text { NS }(0.00 \\
0.25 \\
0.50)\end{array}$ & $\begin{array}{c}\mathrm{VS}_{\mathrm{v}} \\
(0.75, \\
1.00, \\
1.00)\end{array}$ & $\begin{array}{c}\text { NS }(0.00 \\
0.25 \\
0.50)\end{array}$ & $\begin{array}{c}\text { NS }(0.00 \\
0.25 \\
0.50)\end{array}$ & $\begin{array}{c}\text { NS }(0.00 \\
0.25 \\
0.50)\end{array}$ & $\begin{array}{c}\text { NS }(0.00 \\
0.25 \\
0.50)\end{array}$ & $\begin{array}{c}\text { NS }(0.00 \\
0.25 \\
0.50)\end{array}$ & $\begin{array}{c}\mathrm{VS}_{\mathrm{v}} \\
(0.75, \\
1.00, \\
1.00)\end{array}$ & $\begin{array}{c}\mathrm{S}_{\mathrm{v}}(0.50 \\
0.75 \\
1.00)\end{array}$ \\
\hline S4 & $\begin{array}{c}\text { NS }(0.00 \\
0.25 \\
0.50)\end{array}$ & $\begin{array}{c}\mathrm{QS}_{\mathrm{v}} \\
(0.25,\end{array}$ & $\begin{array}{c}\mathrm{VS}_{\mathrm{v}} \\
(0.75,\end{array}$ & $\begin{array}{c}\mathrm{VS}_{\mathrm{v}} \\
(0.75,\end{array}$ & $\begin{array}{c}\mathrm{VS}_{\mathrm{v}} \\
(0.75,\end{array}$ & $\begin{array}{c}\text { NS }(0.00 \\
0.25 \\
0.50)\end{array}$ & $\begin{array}{c}\text { NS }(0.00 \\
0.25 \\
0.50)\end{array}$ & $\begin{array}{c}\mathrm{QS}_{\mathrm{v}} \\
(0.25\end{array}$ & $\begin{array}{c}\text { NS }(0.00 \\
0.25 \\
0.50)\end{array}$ \\
\hline
\end{tabular}




\begin{tabular}{|c|c|c|c|c|c|c|c|c|c|}
\hline & & 0.50, & 1.00, & 1.00, & 1.00, & & & 0.50, & \\
& & $0.75)$ & $1.00)$ & $1.00)$ & $1.00)$ & & & $0.75)$ & \\
\hline S5 & NS (0.00, & NS (0.00, & NS (0.00, & NS (0.00, & NS (0.00, & VS $_{\mathrm{v}}$ & VS $_{\mathrm{v}}$ & NS (0.00, & NS (0.00, \\
& 0.25, & 0.25, & 0.25, & 0.25, & 0.25, & $(0.75$, & $(0.75$, & 0.25, & 0.25, \\
& $0.50)$ & $0.50)$ & $0.50)$ & $0.50)$ & $0.50)$ & 1.00, & 1.00, & $0.50)$ & $0.50)$ \\
& & & & & & $1.00)$ & $1.00)$ & & \\
\hline
\end{tabular}

Table 3. The aggregated decision matrix of best non-fuzzy performance

\begin{tabular}{|l|l|l|l|l|l|l|l|l|l|}
\hline & $\mathbf{C r}_{1}$ & $\mathbf{C r}_{\mathbf{2}}$ & $\mathbf{C r}_{\mathbf{3}}$ & $\mathbf{C r}_{\mathbf{4}}$ & $\mathbf{C r}_{\mathbf{5}}$ & $\mathbf{C r}_{\mathbf{6}}$ & $\mathbf{C r}_{\mathbf{7}}$ & $\mathbf{C r}_{\mathbf{8}}$ & $\mathbf{C r}_{\mathbf{9}}$ \\
\hline S1 & 0.58 & 0.75 & 0.50 & 0.78 & 0.78 & 0.64 & 0.25 & 0.25 & 0.25 \\
\hline S2 & 0.67 & 0.64 & 0.25 & 0.92 & 0.81 & 0.81 & 0.92 & 0.64 & 0.78 \\
\hline S3 & 0.25 & 0.25 & 0.25 & 0.25 & 0.86 & 0.86 & 0.25 & 0.25 & 0.25 \\
\hline S4 & 0.25 & 0.25 & 0.25 & 0.25 & 0.78 & 0.25 & 0.25 & 0.25 & 0.25 \\
\hline S5 & 0.25 & 0.92 & 0.25 & 0.25 & 0.92 & 0.69 & 0.25 & 0.25 & 0.50 \\
\hline & $\mathbf{C r}_{10}$ & $\mathbf{C r}_{11}$ & $\mathbf{C r}_{12}$ & $\mathbf{C r}_{13}$ & $\mathbf{C r}_{14}$ & $\mathbf{C r}_{15}$ & $\mathbf{C r}_{16}$ & $\mathbf{C r}_{17}$ & $\mathbf{C r}_{18}$ \\
\hline S1 & 0.25 & 0.25 & 0.25 & 0.25 & 0.25 & 0.25 & 0.25 & 0.25 & 0.25 \\
\hline S2 & 0.67 & 0.25 & 0.25 & 0.25 & 0.25 & 0.25 & 0.25 & 0.25 & 0.25 \\
\hline S3 & 0.25 & 0.92 & 0.25 & 0.25 & 0.25 & 0.25 & 0.25 & 0.92 & 0.81 \\
\hline S4 & 0.25 & 0.78 & 0.92 & 0.92 & 0.92 & 0.25 & 0.25 & 0.33 & 0.47 \\
\hline S5 & 0.25 & 0.25 & 0.25 & 0.25 & 0.25 & 0.92 & 0.86 & 0.25 & 0.25 \\
\hline
\end{tabular}

Table 4. The normalized importance weight

\begin{tabular}{|l|l|l|l|l|l|l|l|l|l|}
\hline & $\mathbf{C r}_{\mathbf{1}}$ & $\mathbf{C r}_{\mathbf{2}}$ & $\mathbf{C r}_{\mathbf{3}}$ & $\mathbf{C r}_{\mathbf{4}}$ & $\mathbf{C r}_{\mathbf{5}}$ & $\mathbf{C r}_{\mathbf{6}}$ & $\mathbf{C r}_{\mathbf{7}}$ & $\mathbf{C r}_{\mathbf{8}}$ & $\mathbf{C r}_{\mathbf{9}}$ \\
\hline S1 & 0.865 & 0.815 & 1 & 0.847 & 0.847 & 0.744 & 0.271 & 0.390 & 0.320 \\
\hline S2 & 1 & 0.695 & 0.5 & 1 & 0.880 & 0.941 & 1 & 1 & 1 \\
\hline S3 & 0.373 & 0.271 & 0.5 & 0.271 & 0.934 & 1 & 0.271 & 0.390 & 0.320 \\
\hline S4 & 0.373 & 0.271 & 0.5 & 0.271 & 0.847 & 0.290 & 0.271 & 0.390 & 0.320 \\
\hline S5 & 0.373 & 1 & 0.5 & 0.271 & 1 & 0.802 & 0.271 & 0.390 & 0.64 \\
\hline & $\mathbf{C r}_{10}$ & $\mathbf{C r}_{11}$ & $\mathbf{C r}_{12}$ & $\mathbf{C r}_{13}$ & $\mathbf{C r}_{14}$ & $\mathbf{C r}_{15}$ & $\mathbf{C r}_{16}$ & $\mathbf{C r}_{17}$ & $\mathbf{C r}_{18}$ \\
\hline S1 & 0.373 & 0.271 & 0.271 & 0.271 & 0.271 & 0.271 & 0.290 & 0.271 & 0.308 \\
\hline S2 & 1 & 0.271 & 0.271 & 0.271 & 0.271 & 0.271 & 0.290 & 0.271 & 0.308 \\
\hline S3 & 0.373 & 1 & 0.271 & 0.271 & 0.271 & 0.271 & 0.290 & 1 & 1 \\
\hline S4 & 0.373 & 0.847 & 1 & 1 & 1 & 0.271 & 0.290 & 0.358 & 0.580 \\
\hline S5 & 0.373 & 0.271 & 0.271 & 0.271 & 0.271 & 1 & 1 & 0.271 & 0.308 \\
\hline
\end{tabular}

suffered by these patients. These patient datasheets have been diagnosed by a TCM physician manually. Fig. 3 shows patient datasheets.

The simulations were conducted to compare the result from Fuzzy MAGDM with the result from diagnosing manually by a TCM physician. Table 6 indicates the simulation result of a comparison between Fuzzy MAGDM and a TCM physician. As we can see that both results show the same result.

Meanwhile, Table 6 indicates the simulation result of nine patients with ID P17, P21, P28, P31, $\mathrm{P} 40, \mathrm{P} 44, \mathrm{P} 53, \mathrm{P} 78$, and $\mathrm{P} 85$. The simulation result to determine the syndrome differentiation of patients with ID P17 is lung yin deficiency (S5). Because the highest of the alternative preference values $\left(V_{i}\right)$ is a $V_{5}$ with a value of 3.01. For patients with ID P21, $\mathrm{P} 28$, and P31, the simulation results indicate the syndrome differentiations are lung qi deficiency (S4). For patients with ID P40, P44, and P53, the simulation results indicate the syndrome differentiations are the accumulation of heat in the lungs (S2). For the patient with ID P78 and P85, the

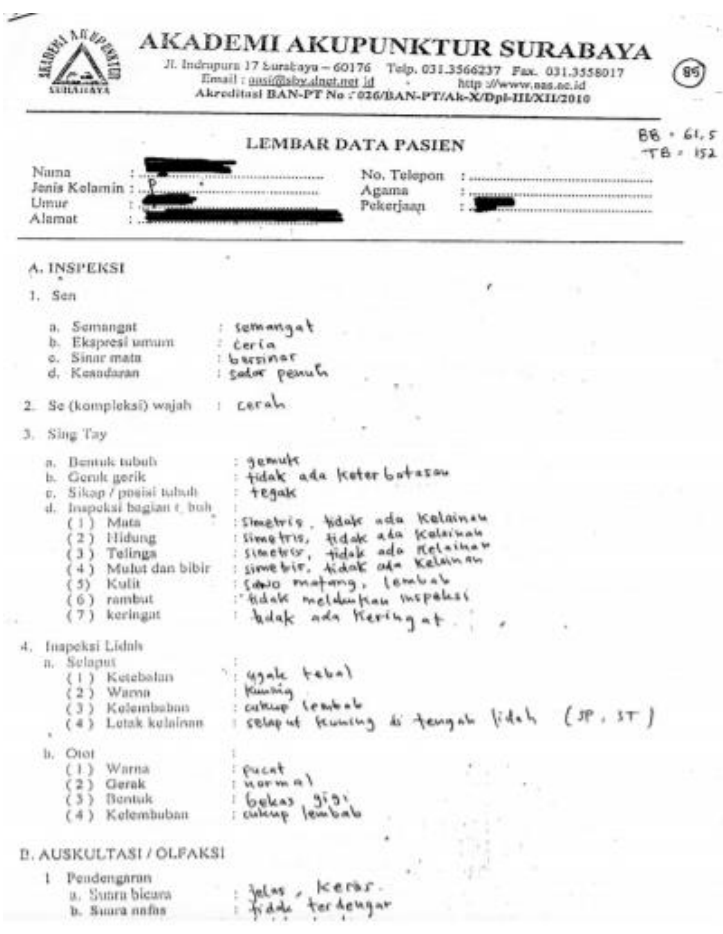

Figure. 3 A patient datasheet

DOI: $10.22266 /$ ijies2021.0430.41 
Table 5. The expert's linguistic preference toward symptoms

\begin{tabular}{|c|c|c|c|c|c|c|c|c|c|}
\hline ID & $\mathbf{C t}_{1}$ & $\mathrm{Ct}_{2}$ & $\mathrm{Ct}_{3}$ & $\mathrm{Ct}_{4}$ & $\mathrm{Ct}_{5}$ & $\mathrm{Ct}_{6}$ & $\mathrm{Ct}_{7}$ & Ct 8 & $\mathrm{Ct}_{9}$ \\
\hline P17 & $\mathrm{NE}$ & $\mathrm{NE}$ & NE & $\mathrm{NE}$ & $S_{v}$ & $S_{v}$ & $\mathrm{NE}$ & $\mathrm{NE}$ & NE \\
\hline P21 & $\mathrm{NE}$ & $\mathrm{NE}$ & NE & $\mathrm{NE}$ & $\mathrm{S}_{\mathrm{v}}$ & NE & $\mathrm{NE}$ & $\mathrm{NE}$ & $\mathrm{NE}$ \\
\hline P28 & $\mathrm{NE}$ & $\mathrm{NE}$ & $\mathrm{NE}$ & $\mathrm{NE}$ & $S_{v}$ & $\mathrm{NE}$ & $\mathrm{NE}$ & $\mathrm{NE}$ & NE \\
\hline P31 & $\mathrm{NE}$ & NE & NE & NE & $\mathrm{VS}_{\mathrm{v}}$ & $\mathrm{NE}$ & $\mathrm{NE}$ & $\mathrm{NE}$ & $\mathrm{NE}$ \\
\hline P40 & $\mathrm{NE}$ & NE & NE & $S_{v}$ & $\mathrm{NE}$ & NE & $\mathrm{NE}$ & $\mathrm{NE}$ & NE \\
\hline P44 & $\mathrm{NE}$ & $\mathrm{NE}$ & $\mathrm{NE}$ & $\mathrm{NE}$ & $\mathrm{S}_{\mathrm{v}}$ & $\mathrm{NE}$ & $\mathrm{S}_{\mathrm{v}}$ & $\mathrm{NE}$ & $\mathrm{NE}$ \\
\hline P53 & $\mathrm{NE}$ & $\mathrm{NE}$ & $\mathrm{NE}$ & $\mathrm{NE}$ & NX & $\mathrm{NE}$ & $\mathrm{NE}$ & $\mathrm{NE}$ & NE \\
\hline P78 & $\mathrm{NE}$ & $\mathrm{NE}$ & $S_{v}$ & $\mathrm{NE}$ & $S_{v}$ & NE & $\mathrm{NE}$ & $\mathrm{NE}$ & NE \\
\hline P85 & $\mathrm{QS}_{\mathrm{v}}$ & $\mathrm{QS}_{\mathrm{v}}$ & $\mathrm{NE}$ & $\mathrm{NE}$ & $\mathrm{VS}_{\mathrm{v}}$ & $\mathrm{NE}$ & $\mathrm{NE}$ & $\mathrm{NE}$ & NE \\
\hline ID & $\mathrm{Cr}_{10}$ & $\mathrm{Cr}_{11}$ & $\mathbf{C r}_{12}$ & $\mathrm{Cr}_{13}$ & $\mathrm{Cr}_{14}$ & $\mathrm{Cr}_{15}$ & $\mathrm{Cr}_{16}$ & $\mathrm{Cr}_{17}$ & $\mathrm{Cr}_{18}$ \\
\hline P17 & $\mathrm{NE}$ & $\mathrm{NE}$ & NE & $\mathrm{VS}_{\mathrm{v}}$ & NE & NE & $\mathrm{VS}_{\mathrm{v}}$ & $\mathrm{NE}$ & NE \\
\hline P21 & $\mathrm{NE}$ & $S_{v}$ & $\mathrm{NE}$ & $S_{v}$ & $\mathrm{NE}$ & $\mathrm{NE}$ & NX & $\mathrm{QS}_{\mathrm{v}}$ & $\mathrm{NE}$ \\
\hline P28 & $\mathrm{NE}$ & $\mathrm{NE}$ & $S_{v}$ & NEt & $S_{v}$ & $\mathrm{NE}$ & $\mathrm{NE}$ & $\mathrm{NE}$ & $\mathrm{NE}$ \\
\hline P31 & $\mathrm{NE}$ & $\mathrm{NE}$ & $\mathrm{NE}$ & $\mathrm{NE}$ & $\mathrm{QS}_{\mathrm{v}}$ & $\mathrm{NE}$ & $\mathrm{NE}$ & $\mathrm{NE}$ & $\mathrm{NE}$ \\
\hline P40 & $\mathrm{NE}$ & $\mathrm{NE}$ & NE & $\mathrm{NE}$ & $\mathrm{VS}_{\mathrm{v}}$ & $\mathrm{NE}$ & $\mathrm{NE}$ & $\mathrm{NE}$ & NE \\
\hline P44 & $\mathrm{NE}$ & $S_{v}$ & $\mathrm{NE}$ & $\mathrm{NE}$ & $\mathrm{NE}$ & $\mathrm{NE}$ & $\mathrm{NE}$ & $\mathrm{NE}$ & $\mathrm{NE}$ \\
\hline P53 & $S_{v}$ & $\mathrm{NE}$ & NE & $\mathrm{NE}$ & $\mathrm{NE}$ & NE & $\mathrm{NE}$ & $\mathrm{NE}$ & NE \\
\hline P78 & $\mathrm{NE}$ & NE & NE & NE & NE & NE & $\mathrm{NE}$ & $\mathrm{NE}$ & $S_{v}$ \\
\hline P85 & $\mathrm{NE}$ & $\mathrm{VS}_{\mathrm{v}}$ & $\mathrm{NE}$ & $\mathrm{NE}$ & NS & $\mathrm{NE}$ & $\mathrm{NE}$ & $\mathrm{NE}$ & NE \\
\hline
\end{tabular}

Table 6. The simulation result of comparison between fuzzy MAGDM and a TCM physician

\begin{tabular}{|c|c|c|c|c|c|c|c|}
\hline \multirow[t]{2}{*}{ ID Patient } & \multicolumn{5}{|c|}{ Ranking } & \multirow[t]{2}{*}{ Fuzzy MAGDM } & \multirow{2}{*}{$\begin{array}{c}\text { Diagnose } \\
\text { Conventionally } \\
\end{array}$} \\
\hline & $V_{1}$ & $\mathbf{V}_{2}$ & $V_{3}$ & $V_{4}$ & $V_{5}$ & & \\
\hline P17 & 2.23 & 2.59 & 2.49 & 2.58 & 3.01 & S5 & S5 \\
\hline P21 & 1.74 & 1.96 & 2.62 & 2.69 & 1.89 & S4 & S4 \\
\hline P28 & 2.08 & 2.31 & 2.785 & 4.20 & 2.23 & S4 & S4 \\
\hline P31 & 1.52 & 1.75 & 1.62 & 1.87 & 1.69 & S4 & S4 \\
\hline P40 & 1.49 & 1.79 & 1.13 & 1.76 & 1.15 & S2 & S2 \\
\hline P44 & 1.95 & 2.67 & 2.54 & 2.38 & 2.61 & S2 & S2 \\
\hline P53 & 2.37 & 3.22 & 2.91 & 2.73 & 3.11 & S2 & S2 \\
\hline P78 & 2.36 & 2.25 & 3.19 & 2.74 & 2.18 & S3 & S3 \\
\hline P85 & 2.38 & 2.62 & 2.66 & 2.60 & 2.43 & S3 & S3 \\
\hline
\end{tabular}

simulation results indicate the syndrome differentiations are retention of moist phlegm in the lungs (S3). Table 6 also indicates a comparison between simulation results of Fuzzy MAGDM versus a TCM physician diagnoses manually. The comparison shows that the simulation results of Fuzzy MAGDM versus a TCM physician diagnosis conventionally are the same. The research results showed that the utilization of Fuzzy MAGDM to determine lung differentiation syndrome was running well.

Table 6 shows the results of research using Fuzzy MAGDM. The simulation results showed that Fuzzy MAGDM can determine lung differentiation syndrome accurately. Nine patient data was used to be simulated and the simulation result showed the same result as the actual diagnosis. The interesting things from the results of this research are the patients with IDs P21, P28, and P31 produce the diagnosis of the same lung syndrome, namely lung qi deficiency (S4). Although some emerging patient symptoms and rating weights are different. This step becomes an input for Fuzzy MAGDM simulation. However, the simulation result still showed the highest $V_{i}$ in lung qi deficiency when compared with other lung syndromes. It can be seen that the highest $V_{i}$ were in lung qi deficiency syndrome, which was $2.69,4.20$, and 1.87 sequentially when compared with the value of $V_{i}$ in other lung syndromes.

The diagnosis results for patients with IDs P40, P44, and P53 were the accumulation of heat in the lungs (S2) with $V_{i}$ values sequentially as follows 1.79 , 2.67, and 3.22. Although some patient symptoms appear different and the weight rating from the expert also differs, these parameters were utilized as input for Fuzzy MAGDM, the simulation results show that the $V_{i}$ value for the accumulation of heat in the lungs was the highest when compared with other lung syndromes.

In the same way, patients with ID P78 and P85 produced the same diagnosis, namely retention of moist phlegm in the lungs (S3) with $V_{i}$ values, 
respectively as follows 3.19 and 2.66. Although some patient symptoms appear different and weight ratings from the preference expert were also different, these parameters were utilized as input for Fuzzy MAGDM, the simulation results show that the value of $V_{i}$ on the retention of moist phlegm in the lungs was the highest when compared with other lung syndromes. Therefore, the Fuzzy MAGDM simulation was running well because it could simulate following the procedure of research to determine lung differentiation syndrome.

As mentioned before that using actual diagnoses will take quite a long time. Meanwhile, by using Fuzzy MADM, the determination of the syndrome becomes faster because the simulation is carried out with computer-based use on expert group preferences in the form of importance weight. Related to weighting, this research is supported by reference [29] stated that the class labels of new cases in selecting syndromes were predicted automatically originate in the accuracy-weighted majority voting. Therefore, to predict a new case requires the preference of physicians for its weighting. Likewise, this research also used expert's preferences where the expert was more than one person. The weights of expert group preferences were used to determine lung syndrome differentiation. The results showed that the use of important weights on GDM can be used with good results. In line with references [30], related to the beneficial using a computer program, stated that the utilization of computational methods in the form of computer programming can determine syndrome differentiation quicker than determine syndrome differentiation conventionally. As a result, patient medication is more facilitate and quicker [31]. Fuzzy MAGDM application for decision making in determining the differentiation of lung syndrome has the advantage that the diagnosis is faster when compared to conventional methods. This is because knowledge in the form of expert preferences has been embedded in the importance weight on the aggregating stage (stage 2) so that the determination of syndrome differentiation becomes faster and more accurate.

This research was limited to only 9 patient data. In the future, larger patient data will be used so that the Receiver Operating Characteristics (ROC) Curve Analysis method can be used to test the results of determining the differentiation of patient syndromes. Then, the next development is the addition of the patient's symptoms that emerge on the pulse analysis and diagnosis on tongue inspection of the patient.

\section{Conclusion}

In this research, we demonstrated the simulation of Fuzzy MAGDM to determine lung syndrome differentiation. The simulation showed that fuzzy linguistic preferences can be used to capture the 3 experts' preferences to rate the symptoms of lung syndrome. These fuzzy preferences in form of Best Non-fuzzy Performance were the assessment results of the 18 criteria or symptoms of lung syndrome as importance weight of criteria. The importance of weight becomes a source in determining types of lung syndrome. From the 9 patient datasheets, the simulation result showed that the Fuzzy MAGDM simulation successfully showed the lung syndrome differentiation accurately. The simulation results of Fuzzy MAGDM compared with conventional TCM doctor diagnoses showed the same results. In the future, it can be developed to determine syndromes in other organs or be developed to detect all syndromes in TCM perspectives.

\section{Conflicts of Interest}

The author declares no conflict of interest.

\section{Author Contributions}

Conceptualization, I.G.P. Asto Buditjahjanto; methodology, I.G.P. Asto Buditjahjanto; software, I.G.P. Asto Buditjahjanto; formal analysis, I.G.P. Asto Buditjahjanto; writing - original draft preparation, I.G.P. Asto Buditjahjanto; writingreview and editing, I.G.P. Asto Buditjahjanto

\section{References}

[1] Z. Wang, H. Hao, F. Gao, Q. Zhang, J. Zhang, and Y. Zhou, "Multi-attribute decision making on reverse logistics based on DEA-TOPSIS: A study of the Shanghai End-of-life vehicles industry", J. Clean. Prod., Vol. 214, pp. 730 737, 2019, doi: 10.1016/j.jclepro.2018.12.329.

[2] Z. SHI and Q. ZHU, "Network selection based on multiple attribute decision making and group decision making for heterogeneous wireless networks", J. China Univ. Posts Telecommun., Vol. 19, No. 5, pp. 92-114, 2012, doi: 10.1016/S1005-8885(11)60305-1.

[3] A. Liu, Y. Xiao, H. Lu, S.-B. Tsai, and W. Song, "A fuzzy three-stage multi-attribute decisionmaking approach based on customer needs for sustainable supplier selection", J. Clean. Prod., Vol. 239, p. 118043, Dec. 2019, doi: 10.1016/j.jclepro.2019.118043.

[4] D. Song and J. Wang, "Supplier Selection Problem Based on Interval Intuitionistic Fuzzy 
Multiattribute Group Decision Making", Open J. Bus. Manag., Vol. 07, No. 03, pp. 1494-1503, 2019, doi: 10.4236/ojbm.2019.73103.

[5] P. P. Mohanty, S. S. Mahapatra, A. Mohanty, and Sthitapragyan, "A novel multi-attribute decision making approach for selection of appropriate product conforming ergonomic considerations", Oper. Res. Perspect., Vol. 5, pp. 82-93, 2018, doi: 10.1016/j.orp.2018.01.004.

[6] M. Akram, W. A. Dudek, and F. Ilyas, "Group decision-making based on pythagorean fuzzy TOPSIS method", Int. J. Intell. Syst., Vol. 34, No. 7, pp. 1455-1475, 2019, doi: 10.1002/int.22103.

[7] Y. Xu, X. Wen, and W. Zhang, "A two-stage consensus method for large-scale multi-attribute group decision making with an application to earthquake shelter selection", Comput. Ind. Eng., Vol. 116, pp. 113-129, 2018, doi: 10.1016/j.cie.2017.11.025.

[8] S. Xian, Z. Yang, and H. Guo, "Double parameters TOPSIS for multi-attribute linguistic group decision making based on the intuitionistic Z-linguistic variables", Appl. Soft Comput., Vol. 85, p. 105835, 2019, doi: 10.1016/j.asoc.2019.105835.

[9] N. Han, S. Qiao, G. Yuan, P. Huang, D. Liu, and K. Yue, "A novel Chinese herbal medicine clustering algorithm via artificial bee colony optimization", Artif. Intell. Med., Vol. 101, p. 101760, 2019, doi: 10.1016/j.artmed.2019.101760.

[10] N. L. Zhang, S. Yuan, T. Chen, and Y. Wang, "Latent tree models and diagnosis in traditional Chinese medicine", Artif. Intell. Med., Vol. 42, No. 3, pp. 229-245, 2008, doi: 10.1016/j.artmed.2007.10.004.

[11] X. Zhou, S. Chen, and B. Liu, "Development of traditional Chinese medicine clinical data warehouse for medical knowledge discovery and decision support", Artif. Intell. Med., Vol. 48, No. 2-3, pp. 139-152, 2010, doi: 10.1016/j.artmed.2009.07.012.

[12] D. Zhang, B. Pang, N. Li, K. Wang, and H. Zhang, "Computerized Diagnosis from Tongue Appearance Using Quantitative Feature Classification", Am. J. Chin. Med., Vol. 33, No. 06, pp. 859-866, 2005, doi: 10.1142/S0192415X05003466.

[13] W. Zhu, Y. Lin, S. K. Cheng, C. Fu, and Y. N. Han, Essence of Traditional Chinese Medicine. WORLD SCIENTIFIC, 2018.

[14] T. Yu, J. Li, Q. Yu, Y. Tian, and X. Shun, "Knowledge graph for TCM health preservation: Design, construction, and applications", Artif. Intell. Med., Vol. 77, pp. 48-52, 2017, doi: 10.1016/j.artmed.2017.04.001.

[15] Y. Liu, C. Eckert, G. Yannou-Le Bris, and G. Petit, "A fuzzy decision tool to evaluate the sustainable performance of suppliers in an agrifood value chain", Comput. Ind. Eng., Vol. 127, pp. 196-212, 2019, doi: 10.1016/j.cie.2018.12.022.

[16] R. P. Kusumawardani and M. Agintiara, "Application of Fuzzy AHP-TOPSIS Method for Decision Making in Human Resource Manager Selection Process", Procedia Comput. Sci., Vol. 72, pp. 638-646, 2015, doi: 10.1016/j.procs.2015.12.173.

[17] Marimin, M. Umano, I. Hatono, and H. Tamura, "Linguistic labels for expressing fuzzy preference relations in fuzzy group decision making”, IEEE Trans. Syst. Man Cybern. Part B, Vol. 28, No. 2, pp. 205-218, 1998, doi: $10.1109 / 3477.662760$.

[18] J. Pang, J. Liang, and P. Song, "An adaptive consensus method for multi-attribute group decision making under uncertain linguistic environment", Appl. Soft Comput., Vol. 58, pp. 339-353, 2017, doi: 10.1016/j.asoc.2017.04.039.

[19] J. Lu, G. Zhang, D. Ruan, and F. Wu, MultiObjective Group Decision Making, Vol. 6. Imperial College Press, 2007.

[20] H. M. Elzarka, H. Yan, and D. Chakraborty, "A vague set fuzzy multi-attribute group decisionmaking model for selecting onsite renewable energy technologies for institutional owners of constructed facilities", Sustain. Cities Soc., Vol. 35, pp. 430-439, 2017, doi: 10.1016/j.scs.2017.08.025.

[21] A. İ. Ölçer, C. Tuzcu, and O. Turan, "An integrated multi-objective optimisation and fuzzy multi-attributive group decision-making technique for subdivision arrangement of RoRo vessels", Appl. Soft Comput., Vol. 6, No. 3, pp. 221-243, 2006, doi: 10.1016/j.asoc.2005.01.004.

[22] L. Mohamed, "An Intelligent Network Selection Strategy Based on MADM Methods in Heterogeneous Networks", Int. J. Wirel. Mob. Networks, Vol. 4, No. 1, pp. 83-96, 2012, doi: 10.5121/ijwmn.2012.4106.

[23] W. H. Xinnong Cheng, Zhu Bing, Acupuncture Therapeutics. Singing Dragon: People's Military Medical Press, 2011.

[24] M. Nikolić, M. Šelmić, D. Macura, and J. Ćalić, "Bee Colony Optimization metaheuristic for fuzzy membership functions tuning", Expert Syst. Appl., Vol. 158, p. 113601, 2020, doi: 10.1016/j.eswa.2020.113601. 
[25] X. Li, X. Wang, G. Lang, and H. Yi, "Conflict analysis based on three-way decision for triangular fuzzy information systems", Int. J. Approx. Reason., 2020, doi: 10.1016/j.ijar.2020.12.004.

[26] T. Chang and T. Wang, "Using the fuzzy multicriteria decision making approach for measuring the possibility of successful knowledge management", Inf. Sci. (Ny)., Vol. 179, No. 4, pp. 355-370, 2009, doi: 10.1016/j.ins.2008.10.012.

[27] T.-Y. Hsieh, S.-T. Lu, and G.-H. Tzeng, "Fuzzy MCDM approach for planning and design tenders selection in public office buildings", Int. J. Proj. Manag., Vol. 22, No. 7, pp. 573-584, 2004, doi: 10.1016/j.ijproman.2004.01.002.

[28] A. Buditjahjanto, "Determination of the Type of Heart Syndrome in Traditional Chinese Medicine with the Bayesian Network Method", J. Infotel, Vol. 12, No. 2, pp. 32-38, 2020, doi: 10.20895/infotel.v12i2.478.

[29] Y. Wang, L. Ma, and P. Liu, "Feature selection and syndrome prediction for liver cirrhosis in traditional Chinese medicine", Comput. Methods Programs Biomed., Vol. 95, No. 3, pp. 249-257, 2009, doi: 10.1016/j.cmpb.2009.03.004.

[30] Z. Liang, J. Liu, A. Ou, H. Zhang, Z. Li, and J. $X$. Huang, "Deep generative learning for automated EHR diagnosis of traditional Chinese medicine", Comput. Methods Programs Biomed., Vol. 174, pp. 17-23, 2019, doi: 10.1016/j.cmpb.2018.05.008.

[31] Q. Zhang, C. Bai, Z. Chen, P. Li, S. Wang, and H. Gao, "Smart Chinese medicine for hypertension treatment with a deep learning model", J. Netw. Comput. Appl., Vol. 129, pp. 1-8, 2019, doi: 10.1016/j.jnca.2018.12.012. 